\title{
The Determinants of Health: Neighborhood Characteristics, Obesity and the Mental Health of African-American Adolescent Girls
}

\author{
Roseanne L. Flores \\ Department of Psychology, Hunter College of the City University of New York, New York, USA \\ Email:rflores@hunter.cuny.edu
}

How to cite this paper: Flores, R.L. (2016) The Determinants of Health: Neighborhood Characteristics, Obesity and the Mental Health of African-American Adolescent Girls. Open Journal of Social Sciences, 4, 126-136. http://dx.doi.org/10.4236/jss.2016.412012

Received: October 27, 2016

Accepted: December 27, 2016

Published: December 30, 2016

Copyright $\odot 2016$ by author and Scientific Research Publishing Inc. This work is licensed under the Creative Commons Attribution International License (CC BY 4.0).

http://creativecommons.org/licenses/by/4.0/

\begin{abstract}
The present study examined the relationship among neighborhood characteristics, obesity, and the mental health outcomes of a nationally representative sample of African-American adolescent girls between the ages of 12 - 17. Using data from the 2011/2012 National Survey of Children's Health, four questions were extracted to measure neighborhood amenities, neighborhood detractors, body mass index, and experience of depression. Ordinal regressions were calculated to estimate the relationships between all variables. The results indicated that over $25 \%$ of AfricanAmerican girls, ages 12 - 14 were overweight and obese with fewer 15 - 17-year-old girls falling within these categories. African-American girls had access to fewer amenities in their communities while at the same time being exposed to more detracting elements within their neighborhoods. Finally over $25 \%$ of parents or caregivers reported that girls ages 12 - 17 expressed being depressed in the last 12 months and depression was found to be related to obesity. Overall, African-American adolescent girls tended to live in communities with fewer resources and were at greater risk for being overweight and obese and having poorer mental health outcomes than their white peers. They were also the least likely to receive mental health services. In addition, access to neighborhood amenities had been shown to lead to better health outcomes. Given the positive relationship between neighborhood amenities, access to quality healthcare and health outcomes, local, state, and federal governments should continue to advocate for the provision of resources to communities with a substantial number of detracting elements so as to reduce the health disparities within the community. In addition, psychologists and other health providers should continue to advocate for mental health services for African-American girls who are the least likely to receive them.
\end{abstract}

\section{Keywords}

Determinants of Health, African-American, Mental Health, Adolescents, Girls, 
Obesity

\section{Introduction}

Over the last 20 years obesity has been on the rise within the United States. From the 1990 's until the present, the nation has gone from being mildly overweight to the current crisis where vast sectors of the population are overweight and obese (CDC, 2012) [1]. In general, while the nation has seen an overall increase in obesity, certain areas of the population have suffered more from this disease. According to the definition of the Centers of Disease Control (CDC), "overweight" is defined as having access body weight for a particular height from fat, muscle, bone, water, or a combination of these factors and "obesity" is defined as having excess body fat (CDC, 2012) [1]. To date, the research has shown that African-American girls and women are at the greatest risk for becoming obese (Sherwood, Story, \& Obaszanek, 2004 [2]; Nelson \& Story, 2009 [3]). In addition to poor physical health outcomes, obesity has also been shown to have a negative impact on the mental health of adolescents (Ogden, et al., 2006) [4]. The question that arises is why this group over others? According to Sherwood, Story \& Obasrzanek (2004) [2], there are several correlates of obesity in African-American girls, such as dietary factors, television viewing, physical activity level, and low socioeconomic status which places this group at risk. Taking those correlates into account, previous research has focused on low-socioeconomic status as being a critical factor that often leads to the lack of access to high quality food which in turn leads to obesity (Kumanuika, 2007 [5]; Odoms-Young, Zenk \& Mason, 2009 [6]). That being said, while having a low-income may be an important underlying cause which contributes to overweight and obesity in African-American girls, researchers such as James Jackson, have suggested that it cannot be the only factor, because African-American women and girls across all income levels are experiencing high incidences of overweight and obesity within the United States. He proposes that because high rates of obesity are not isolated within one socioeconomic group of African-Americans, going forward researchers will need to take a closer look at the effect of other social determinants of health on this health disparity (Jackson, Knight, \& Rafferty, 2010; American Psychological Association, 2014) [7] [8].

According to the National Institutes of Health, "social determinants of health are conditions in the environments in which people are born, live, learn, work, play, worship, and age that affect a wide range of health, functioning, and quality-of-life outcomes and risks" (NIH, Healthy People, 2020) [9]. In order to understand what is going on within the African-American community, it becomes imperative that we look at other determinants of health. Not only do we need to examine the number of detracting elements in the community, but we also need to examine the number of amenities in a community and the role they play in protecting African-American girls from obesity. Moreover, in addition to addressing the built environments in which adolescents reside 
attention must be given to the relationship between mental health and obesity.

In 2012 [8], the American Psychological Association and the Association of Black Psychology held a "Summit on Obesity in African American Women and Girls". One of the calls of the organizers of the summit was for researchers to address the gap in the field by examining the relationship between mental health and obesity in order to promote healthy behavior. Drawing on the Healthy People 2020 initiative to address health disparities in the African-American community and the call of the American Psychological Association, the purpose of the present study was to examine the relationship among neighborhood characteristics, obesity, and the mental health of a nationally representative sample of African-American adolescent girls between the ages of 12 - 17 . More specifically, the questions addressed were as follows: 1) What is the prevalence of access to neighborhood amenities and the detracting or negative attributes within the communities in which African-American girls live?; 2) Can obesity in African-American girls be predicted from access to neighborhood amenities?; 3) Can obesity in African-American girls be predicted from detracting or negative neighborhood attributes?; and finally 4) What is the relationship between mental health and obesity for AfricanAmerican girls?

\section{Method}

\subsection{Dataset and Design}

The National Survey of Children's Health (NSCH) 2011/12 is a nationally representative survey of US households with children ranging in age from 0 - 17 with a total of 95,677 child level interviews having been completed. The purpose of the NSCH is to assess the emotional and physical health as well as child well-being. The respondents were parents or guardians with knowledge of the health and healthcare of the target child. The survey uses a complex survey design and is stratified by state and sample type (landline or cell-phone). The survey was funded by United States Department of Health and Human Services, Health Resources and Services Administration, and the Maternal and Child Health Bureau (Center for Disease Control and Prevention, 2013) [10].

\subsection{Participants}

The demographic data for the NSCH survey includes indictors for US children by age group, sex of the child, the race and ethnicity distribution of the child population, the level of the child's household income, children living in working poor households, and quality of the neighborhood. The sample for the current study consisted of data for 1623 African American girls ages 12 - 17.

\subsection{Variables}

The study consisted of two outcomes variables: child's mental health and obesity status as well as two predictor variables neighborhood amenities and neighborhood detractors. 


\section{Outcome Variables}

\subsection{Mental Health}

Mental health was assessed using the following question: "How often was this true for (child) during the past month: (He/she) is unhappy, sad, or depressed?" Parental/caregiver could respond as follows: never, rarely, sometimes, or (usually/always).

\subsection{Obesity and Overweight}

Obesity and overweight were assessed by Body Mass Index (BMI). BMI was measured by the following question "What is the weight status of children based on Body Mass Index (BMI) for age? The BMI was derived from the public use data file provided by the National Center for Health Statistics. Response categories were as follows: Underweightless than the 5th percentile; Healthy weight-5th percentile to less than the 85th percentile; Overweight-85th to less than the 95th percentile; and Obese-equal to or greater than the 95th percentile.

\subsection{Predictor Variables}

\subsubsection{Neighborhood and Community Characteristics}

Access to neighborhood amenities were measured using the following question: "How many children live in neighborhoods that contain certain amenities-parks, recreation centers, sidewalks or libraries?" Responses included: none, one of four, two of four, three of four, and all four.

\subsubsection{Detracting Neighborhood Elements}

Exposure to detracting neighborhood elements was evaluated using the following question: "How many children live in neighborhoods with detracting elements-vandalism, rundown housing or litter?” Responses included: none, one of three, two of three, all three.

Additional factors in the model included age, race, and gender. All factors were included in all models.

\section{Data Analysis}

Descriptive statistics were calculated for the sample of African-American girls ages 12 17 frequency of reporting being depressed, BMI, the number of neighborhood amenities, and number of neighborhood detractors.

Statistical analyses were performed using SPSS 17 Complex Sample module to account for the complex survey design of NSCH survey. Data were weighted using the final sampling weight NSCHWT, stratum identifiers (STATE and SAMPLE) as well as the PSU (IDNUMR) provided in the dataset to calculate the proper variance estimation. Unweighted descriptive statistics were calculated. Ordinal regressions were performed for the two outcome variables obesity and mental health. Both models included all independent variables as well as the factors for age, race and gender. 


\section{Results}

\subsection{Prevalence of Neighborhood Characteristics, Obesity and Mental Health Outcomes}

Descriptive statistics were computed for adolescent girls between the ages of 12 - 17 . $49.2 \%$ were 12 - 14 years of age and $51 \%$ were between the ages of 15 - 17. Girls between 12 - 14 years of age were reported to have healthy weight whereas $27.1 \%$ were either overweight or obese. With respect to neighborhood characteristics $24.4 \%$ of girls within the 12 - 14 year old age group were reported as having at least two amenities within their neighborhoods, with $33.6 \%$ of the girls' caregivers reporting they had 3 or more detracting elements within their communities. Almost half (46.7\%) of the 12 14 year old girls were reported as never feeling sad or depressed within the past 12 months.

Of the 15 - 17 year old girls 78.4\% were reported as having healthy weight whereas $17.9 \%$ were classified as either overweight or obese. Approximately $16 \%$ of the $15-17$ year old girls had either 2 or 4 amenities within their neighborhoods, $33.6 \%$ were reported as having 3 detracting elements in their neighborhoods and $42.4 \%$ were reported as never having experienced depression within the last 12 months (Table 1 provides the weighted and unweighted estimates for each variable).

\subsection{Neighborhood Characteristics and Obesity}

\subsubsection{Access to Neighborhood Amenities and Obesity}

Ordinal regression was conducted to determine which independent variable (age, race, gender and access to neighborhood amenities) were predictors for obesity. The overall model of 4 predictors accounted for $2.5 \%$ (Nagelkerke $=0.025$ ) of the explanation for the BMI of adolescent girls. Wald statistics indicated that all variables significantly predicted BMI (Table 2).

Table 3 displays the cumulative odds ratios for number of neighborhood amenities. All odds ratios indicated a decrease 0 - 3 amenities vs all four in the neighborhood.

\subsubsection{Neighborhood Detractors and Obesity}

Ordinal regression was conducted to determine which independent variable (age, race, gender or number of detracting elements in the neighborhood) were predictors for obesity in adolescent girls. The overall model of 4 predictors accounted for $2.6 \%$ (Nagelkerke $=0.026)$ of the explanation for the BMI of adolescent girls. Wald statistics indicated that all variables significantly predicted BMI (Table 4).

Table 5 displays the cumulative odds ratios for number of detracting elements in neighborhoods. The odds ratio 1.180 indicates that the cumulative odds for a having no detracting elements in the neighborhood is 1.180 times the cumulative odds for having 3 detracting elements.

\subsubsection{Obesity and Depression}

Ordinal regression was conducted to determine which independent variable (age, race, gender and experience of depression) were predictors for obesity in adolescent girls. 
Table 1. Demographic information for African-American girls ages 12 - 14 and 15 - 17.

\begin{tabular}{|c|c|c|}
\hline & Weighted Estimates & Unweighted Estimates \\
\hline & $903,793.676$ & $796(49.2 \%)$ \\
\hline & $947,556.758$ & $827(51.0 \%)$ \\
\hline & $187,909.530$ & $287(5.0 \%)$ \\
\hline & $2,535,979.539$ & $3976(67.9 \%)$ \\
\hline & $603,681.280$ & $763(16.2 \%)$ \\
\hline & $405,466.082$ & $494(10.9 \%)$ \\
\hline \multicolumn{3}{|l|}{ Characteristics } \\
\hline & $148,268.662$ & $270(3.8 \%)$ \\
\hline & $3,094,781.099$ & $5152(78.4 \%)$ \\
\hline & $390,381.109$ & $619(9.9 \%)$ \\
\hline & $314,758.605$ & $403(8.0 \%)$ \\
\hline & $36,234.349$ & $21(17.7 \%)$ \\
\hline & $97,253.300$ & $62(24.4 \%)$ \\
\hline & $88,634.877$ & $9(11.7 \%)$ \\
\hline & $220,360.386$ & $174(15.1 \%)$ \\
\hline Female & $444,986.594$ & $436(15.2 \%)$ \\
\hline \multicolumn{3}{|l|}{$(12-14)$} \\
\hline \multirow[t]{5}{*}{$(15-17)$} & $27,442.513$ & $31(11.7 \%)$ \\
\hline & $39,823.314$ & $51(12.1 \%)$ \\
\hline & $117,138.969$ & $95(16.3 \%)$ \\
\hline & $220,646.267$ & $169(15.0 \%)$ \\
\hline & $519,198.770$ & $464(16.6 \%)$ \\
\hline \multicolumn{3}{|l|}{${ }^{* *}$ Number of detracting neighborhood elements } \\
\hline \multicolumn{3}{|l|}{$(12-14)$} \\
\hline No detracting elements in the neighborhood & $594,333.665$ & $547(14.0 \%)$ \\
\hline Neighborhood has 1 detracting element from the list & $177,251.049$ & $132(18.2 \%)$ \\
\hline Neighborhood has 2 detracting element from the list & $54,022.990$ & $59(13.4 \%)$ \\
\hline Neighborhood has 3 detracting element from the list & $62,827.936$ & $46(33.6 \%)$ \\
\hline \multicolumn{3}{|l|}{$(15-17)$} \\
\hline No detracting elements in the neighborhood & $650,890.669$ & $544(14.5 \%)$ \\
\hline Neighborhood has 1 detracting element from the list & $1,515,149.542$ & $148(16.9 \%)$ \\
\hline Neighborhood has 2 detracting element from the list & $96,687.539$ & $74(20.9 \%)$ \\
\hline Neighborhood has 3 detracting element from the list & $33,544.484$ & $37(19.8 \%)$ \\
\hline \multicolumn{3}{|l|}{ Experience of depression within age group } \\
\hline \multicolumn{3}{|l|}{$(12-14)$} \\
\hline Never & $420,539.811$ & $354(46.7 \%)$ \\
\hline Rarely & $211,587.950$ & $226(23.5 \%)$ \\
\hline Sometimes & $254,371.913$ & $189(28.3 \%)$ \\
\hline Usually & 4800.122 & $11(0.5 \%)$ \\
\hline Always & 8545.444 & $14(0.9 \%)$ \\
\hline \multicolumn{3}{|l|}{$(15-17)$} \\
\hline Never & $398,317.781$ & $340(42.4 \%)$ \\
\hline Rarely & $248,242.051$ & $203(26.4 \%)$ \\
\hline Sometimes & $239,231.968$ & $248(25.5 \%)$ \\
\hline Usually & $26,605.687$ & $15(2.8 \%)$ \\
\hline Always & $26,232.896$ & $14(2.8 \%)$ \\
\hline
\end{tabular}

${ }^{*}$ Underweight-Less than the $5^{\text {th }}$ percentile; Healthy weight $-5^{\text {th }}$ percentile to less than the $85^{\text {th }}$ percentile; Overweight $-85^{\text {th }}$ to less than the $95^{\text {th }}$ percentile; Obese-Equal to or greater than the $95^{\text {th }}$ percentile. ${ }^{* *}$ Amenities consist of sidewalks, parks, recreation centers, or libraries. ${ }^{* *}$ Detracting elements consist of litter, poorly kept or rundown housing or vandalism/graffiti. 
Table 2. Regression coefficients for access to neighborhood amenities and obesity.

\begin{tabular}{ccccc}
\hline Source & df1 & df2 & Adjusted Wald F & Significance \\
\hline Age & 1 & 32,509 & 29.834 & 0.001 \\
Race & 1 & 32,509 & 44.319 & 0.001 \\
Gender & 1 & 32,509 & 29.536 & 0.001 \\
Neighborhood Amenities & 3.836 & $124,702.949$ & 6.249 & 0.001 \\
\hline
\end{tabular}

Table 3. Odds ratios for neighborhood amenities.

\begin{tabular}{cccc}
\hline \multirow{2}{*}{ Count of Amenities in Children's Neighborhoods } & Cumulative Odds Ratio & \multicolumn{2}{c}{ Confidence Interval } \\
\cline { 3 - 4 } & & Lower & Upper \\
\hline No amenities vs Neighborhood has all four from the list & 0.705 & 0.569 & 0.874 \\
Neighborhood has 1 amenity vs all 4 from the list & 0.696 & 0.555 & 0.873 \\
Neighborhood has 2 amenities vs all 4 from the list & 0.855 & 0.734 & 0.997 \\
Neighborhood has 3 amenities vs all 4 from the list & 0.803 & 0.703 & 0.918 \\
\hline
\end{tabular}

${ }^{*}$ Amenities consist of sidewalks, parks, recreation centers, or libraries.

Table 4. Regression coefficients for neighborhood detractors and obesity.

\begin{tabular}{ccccc}
\hline Source & df1 & df2 & Adjusted Wald F & Significance \\
\hline Age & 1 & 32,723 & 29.408 & 0.001 \\
Race & 1 & 32,723 & 41.373 & 0.001 \\
Gender & 1 & 32,723 & 28.701 & 0.001 \\
Neighborhood Detractors & 2.782 & $91,026.02$ & 6.937 & 0.001 \\
\hline
\end{tabular}

Table 5. Odds ratios for neighborhood detractors.

\begin{tabular}{cccc}
\hline Count of Detracting Neighborhood Elements & Cumulative Odds Ratio & \multicolumn{2}{c}{ Confidence Interval } \\
\cline { 3 - 4 } & & Lower & Upper \\
\hline $\begin{array}{c}\text { No detracting elements vs Neighborhood has } \\
3 \text { detracting elements from the list } \\
\text { Neighborhood has } 1 \text { detracting element vs } \\
3 \text { detracting elements from the list } \\
\begin{array}{c}\text { Neighborhood has } 2 \text { detracting element vs } \\
3 \text { detracting elements from the list }\end{array}\end{array}$ & 1.180 & 0.873 & 1.595 \\
& 0.925 & 0.671 & 1.274 \\
\hline
\end{tabular}

${ }^{*}$ Detracting elements consist of litter, poorly kept or rundown housing, or vandalism/graffiti.

The overall model of 4 predictors accounted for $2.6 \%$ (Nagelkerke $=0.026)$ of the explanation for the BMI of adolescent girls. Wald statistics indicated that all variables significantly predicted BMI (Table 6).

Table 7 displays the cumulative odds ratios for the experience of depression indicating that the never, rarely or sometimes experiencing depression are 1.551, 1.538 and 1.222 times the cumulative odds for always experiencing depression. 
Table 6. Regression coefficients for mental health and obesity.

\begin{tabular}{ccccc}
\hline Source & df1 & df2 & Adjusted Wald F & Significance \\
\hline Age & 1 & 32,851 & 32.808 & 0.001 \\
Race & 1 & 32,851 & 43.049 & 0.001 \\
Gender & 1 & 32,851 & 32.749 & 0.001 \\
Depression & 3.809 & $125,130.849$ & 5.159 & 0.001 \\
\hline
\end{tabular}

Table 7. Odds ratios for experience of depression.

\begin{tabular}{cccc}
\hline \multirow{2}{*}{ Experience of Depression } & Cumulative Odds Ratio & \multicolumn{2}{c}{ Confidence Interval } \\
\cline { 3 - 4 } & & Lower & Upper \\
\hline Never vs. Always & 1.551 & 0.877 & 2.743 \\
Rarely vs. Always & 1.538 & 0.869 & 2.721 \\
Sometimes vs. Always & 1.222 & 0.690 & 2.164 \\
Usually vs. Always & 0.846 & 0.405 & 1.769 \\
\hline
\end{tabular}

\section{Discussion}

The study examined the relationship between neighborhood characteristics, obesity and the mental health of African-American girls. The present study adds to the work in the field because it directly addresses the relationship between the mental health of African-American girls and their body image. Moreover, it does so within the context of the social determinants of health. The above findings support previous research that has demonstrated that obesity is highest in low-income communities and that minority populations are at the greatest risk for suffering from this disease, with African-American girls and women being at the greatest risk (Ogden et al., 2006) [2]. That being said, the question arises as to what can be done to help combat this problem. In order for the country to make a dent in fighting this disease and turning these trends around, individuals, in this case adolescents and their parents' will have to make changes to their behavior. While it is difficult to make such changes all at once, several intervention and prevention programs have been proposed at the national and local levels that have had some success.

At the national level the CDC has supported a number prevention and intervention programs, which have been implemented at the school and community levels. Such programs include: "the CDC Guide to Strategies to Increase Physical Activity in the Community Obesity Prevention Strategies; the CDC Guide to Strategies to Increase Physical Activity in the Community; the CDC Guide to Strategies to Increase the Consumption of Fruits and Vegetables; the CDC Guide to Breastfeeding Interventions; School Health Guidelines to Promote Healthy Eating and Physical Activity which provides nine guidelines that serve as the foundation for developing, implementing, and evaluating school-based healthy eating and physical activity policies and practices for students in grades K-12 and the Clinical Guidelines on the Identification, Evaluation, 
and Treatment of Overweight and Obesity in Adults" to name but a few programs (CDC, 2011) [11].

Following the lead of the CDC at the local level New York City has developed an exceptional number of excellent prevention and intervention programs to address the growing epidemic of obesity in the city. For example, Green Carts were established across the city and sell only fresh fruits and vegetables. In addition, the Health Department has begun to work with supermarkets in at risk communities across NYC to help improve the access and availability of quality fruits and vegetables in these communities. New York City has also promoted the Healthy Workplace and Heath High School initiatives which promote healthy eating and events around food. Finally, New York City has implemented a program called "Shape Up New York City" which is a free fitness program that is open to all family members in parks, community centers and housing facilities across the City (NYC.gov, 2012) [12].

In order to specifically address the needs of New York City youth, the NYC Department of Health created resources for adolescents and parents. For example, "Teens Speak about Getting Fit" is a resource that was designed by teens for teens, and the brochure on "Helping Children Reach a Healthy Weight: Proven Tips for Parents Brochure" provides parents with some quick ways of helping their children be healthy and maintain their weight. These resources as well as others have been developed to engage young people as well as their parents in maintaining a healthy lifestyle that includes a focus on positive mental health.

In short, the purpose of the present research was to examine the prevalence of obesity in adolescent African-American girls and its relationship to mental health and social determinants of health. The findings supported previous research that indicated that African-American girls have the greatest incidence of overweight and obesity and access to fewer resources within their neighborhoods.

\section{Limitations and Future Research}

Despite the contribution of the findings of the present study to the field some limitations should be noted. First although the study addresses the effect of neighborhood characteristics on the health outcomes of African-American girls it is not clear whether those characteristics are the same within rural, urban or suburban communities. Future research should take these geographical differences into account. In addition, the current study only addresses depression in girls, which is only one form of mental health challenge that girls experience. Future research should take into account the relationship between other mental health challenges experienced by African-American girls and their physical health.

\section{Conclusions}

A number of programs at both national and local levels, which have provided multiple successful supports and mechanisms to address the obesity of children, youth and families within communities were described. That said, while if any, a number of these pro- 
grams have begun to address this epidemic, few if any have been targeted to specific communities, which means that the country is still a long way away from addressing the overall trends in obesity and mental health outcomes for African-American girls.

Obesity is linked to many diseases, such as diabetes, which is currently costing the nation a fortune to treat and if the problem is not attacked on multiple levels the costs will only continue to escalate. In addition, obesity is also linked to poor self-esteem which effects overall well-being and a failure to thrive. It not only affects low-income African-American girls and women, but also African-American women in other income brackets. In order to adequately address this problem, local communities will need to design programs that address needs of the local community because as has been shown what works well for one group does not necessarily work well for another group even when they come from similar individuals. The country would do well to address the other determinants of health that might be the root causes of obesity, such as stress, or risk another outbreak of disease within the African-American community. As demonstrated, the problem is complex, a simple solution will not be sufficient to eradicate the disease. Furthermore, as we move closer to attempting to reduce the cost of health care, if we don't address the root causes of obesity, we will continue to invest in the treatment of this disease and eventually increase, rather than decrease the cost of healthcare in the country. Policy makers would do well to hearken back to the wise words of Benjamin Franklin who stated "an ounce of prevention is worth a pound of cure" [13] not only for African-Americans but for all people suffering from this debilitating disease.

\section{References}

[1] U.S. Department of Health and Human Services, Centers for Disease Control and Prevention (2012) A Growing Problem. http://www.cdc.gov/obesity/childhood/problem.html

[2] Sherwood, N.E., Story, M. and Obarzanek, E. (2004) Correlates of Obesity in AfricanAmerican Girls: An Overview. Obesity Research, 12, 3S-6S. https://doi.org/10.1038/oby.2004.263

[3] Nelson, M.C. and Story, M. (2009) Food Environments in University Dorms: 20,000 Calories per Dorm Room and Counting. American Journal of Preventive Medicine, 36, 523-526. https://doi.org/10.1016/j.amepre.2009.01.030

[4] Ogden, C.L., Carroll, M.D., Curtin, L.R., McDowell, M.A., Tabak, C.J. and Flegal, K.M. (2006) Prevalence of Overweight and Obesity in the United States, 1999-2004. JAMA, 295, 1549-1555. https://doi.org/10.1001/jama.295.13.1549

[5] Kumanyika, S.K. (2008) Environmental Influences on Childhood Obesity: Ethnic and Cultural Influences in Context. Physiology \& Behavior, 94, 61-70.

https://doi.org/10.1016/j.physbeh.2007.11.019

[6] Odoms-Young, A.M., Zenk, S. and Mason, M. (2009) Measuring Food Availability and Access in African-American Communities: Implications for Intervention and Policy. American Journal of Preventive Medicine, 36, S145-S150.

https://doi.org/10.1016/j.amepre.2009.01.001

[7] Jackson, J.S., Knight, K.M. and Rafferty, J.A. (2010) Race and Unhealthy Behaviors: Chronic Stress, the HPA Axis, and Physical and Mental Health Disparities over the Life Course. American Journal of Public Health, 100, 933-939 
[8] American Psychological Association (2014) Summit on Obesity in African-American Women and Girls. Final Report and Action Agenda. http://www.apa.org/pi/women/resources/reports/obesity.pdf

[9] U.S. Department of Health and Human Services, Healthy People 2020 (2012). Social Determinants of Health.

http://www.healthypeople.gov/2020/topicsobjectives2020/overview.aspx?topicid=39

[10] Centers for Disease Control and Prevention, National Center for Health Statistics, State and Local Area Integrated Telephone Survey. 2011-2012 National Survey of Children's Health Frequently Asked Questions. April 2013. http://www.cdc.gov/nchs/slaits/nsch.htm

[11] The CDC Guide to Strategies to Increase Physical Activity in the Community. http://www.cdc.gov/obesity/downloads/pa_2011_web.pdf

[12] Shape of New York City. https://www.nycgovparks.org/programs/recreation/shape-up-nyc

[13] The Electric Ben Franklin. http://www.ushistory.org/franklin/philadelphia/fire.htm

Submit or recommend next manuscript to SCIRP and we will provide best service for you:

Accepting pre-submission inquiries through Email, Facebook, LinkedIn, Twitter, etc.

A wide selection of journals (inclusive of 9 subjects, more than 200 journals)

Providing 24-hour high-quality service

User-friendly online submission system

Fair and swift peer-review system

Efficient typesetting and proofreading procedure

Display of the result of downloads and visits, as well as the number of cited articles

Maximum dissemination of your research work

Submit your manuscript at: http://papersubmission.scirp.org/

Orcontact jss@scirp.org 